\title{
My Core: conveying the everyday normality of living with congenital heart disease
}

\author{
Jo Wray $^{1 \wedge}$, Sofie Layton², Giovanni Biglino ${ }^{3}$ \\ ${ }^{1}$ Centre for Outcomes and Experience Research in Children's Health, Illness and Disability, Great Ormond Street Hospital for Children NHS \\ Foundation Trust, London, UK; ${ }^{2}$ Royal College of Art, London, UK; ${ }^{3}$ Bristol Heart Institute, Bristol Medical School, University of Bristol, Bristol, UK \\ Correspondence to: Dr. Jo Wray. Centre for Outcomes and Experience Research in Children's Health, Illness and Disability, Great Ormond Street \\ Hospital for Children NHS Foundation Trust, Great Ormond Street, London WC1N 3JH, UK. Email: jo.wray@gosh.nhs.uk.
}

Submitted Jun 22, 2021. Accepted for publication Aug 30, 2021.

doi: $10.21037 / \mathrm{cdt}-21-387$

View this article at: https://dx.doi.org/10.21037/cdt-21-387

Feeling different, that others do not understand what it is really like to live with congenital heart disease (CHD) (1), is a frequent lament of patients, sometimes resulting in social isolation and a failure to maximise opportunities afforded by successful treatment. Patients can disengage from health care, with potentially deleterious consequences for themselves and their families, health care systems and wider society. But what is the answer-how do we help patients to normalise their experience whilst at the same time enabling those around them to gain a greater appreciation of what life is like for them? Art-making can be one way of addressing this and we present an example of our experience, engaging patients in the process.

A young man carrying a giant crimson velvet heart to the hospital and leaving the hospital hugging it. Sitting in the waiting room, the heart always next to him. Sitting on a swing at the park, throwing his heart in the air, receiving it. This is the subject of a photographic series (Figure 1) (2) encapsulating key elements of the everyday life of young people born with CHD—-the regular hospital appointments, the burden of, but coexistence with, their hearts, caring for them, protecting them.

The series stems from a participatory process (3) working directly with patients with CHD. During an artistled workshop a teenager was asked to draw an image of how he saw his heart. He created a drawing and collaged an over-sized heart onto a superhero figure, a man inside a giant heart that encased him. There was a simplicity to this design, but it also powerfully conveyed a sense of protection and identity, while the proportions of the organ also suggested both its emotional weight and how large a part of this person's life it occupied.

In a subsequent artistic translation process of this image (4), leading to sharing it with broader audiences (patients, clinicians, the general public), the artist was faced with extrapolating the powerful and literal, albeit potentially clichéd, image of the superhero costume while also respecting the intimacy of the original design. The first step was the creation of an over-sized anatomical heart, achieved by scaling up a 3D virtual model of a heart, creating the anatomical form in solid foam, which was then skilfully cut and shaped into a light-weight hollow heart.

Before deciding on the final construction, and recognising the performative quality of the heart, the artist involved a performer in the process, exploring the possibilities offered by the giant heart-could it be worn as a superhero costume? They explored the movement qualities that it offered and it became clear that wearing the heart as a costume would limit the possibilities of expression. This would restrict the narrative somewhat and the figure would only be able to explore the possibility of being encased (almost trapped) in the heart. It became apparent that creating an oversized sculptural heart would provide a much richer set of narrative options as the heart could literally be taken on a journey-that of the patient.

This is the narrative captured in the series of six photographic images encapsulating different moments in and around the hospital and the relationship between the

^ ORCID: Jo Wray, 0000-0002-4769-1211; Giovanni Biglino, 0000-0003-0413-149X. 

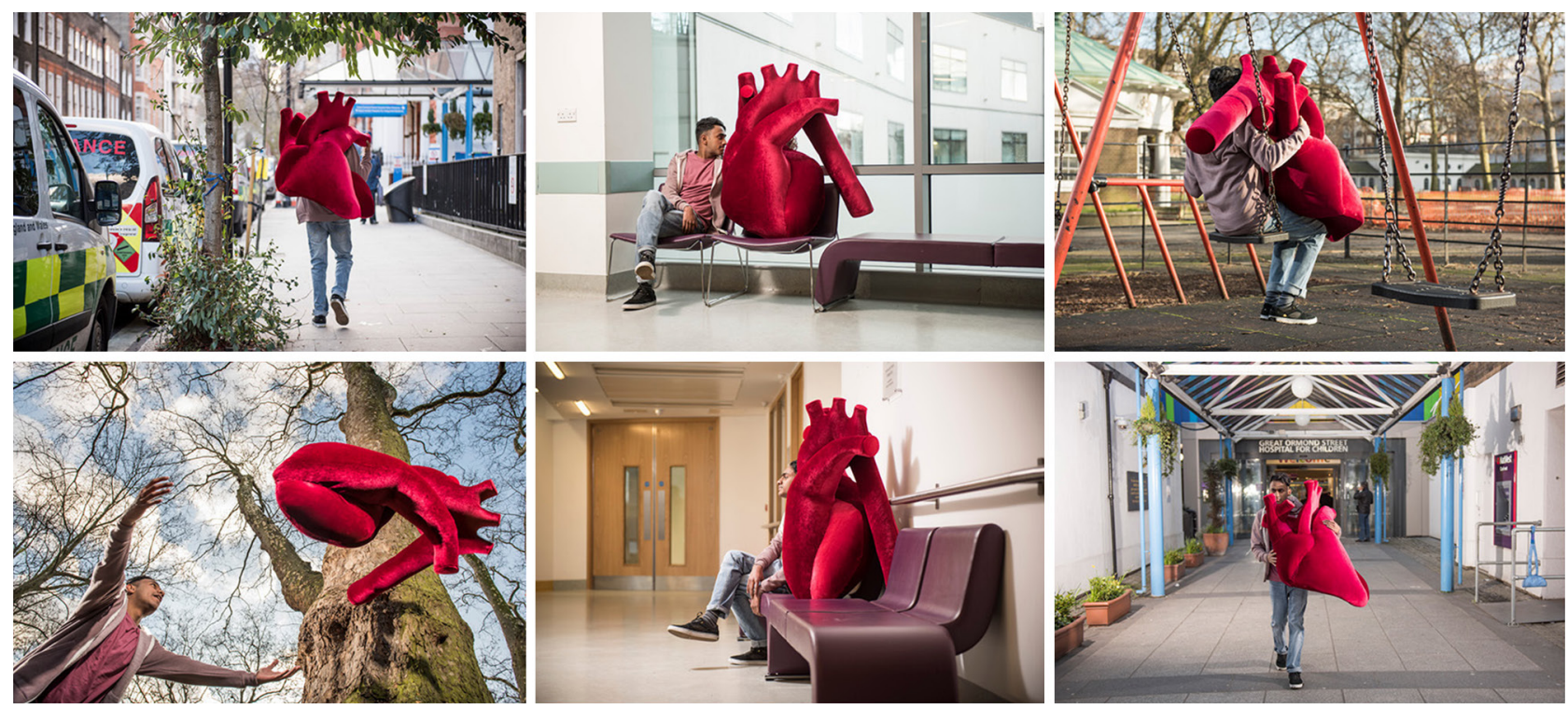

Figure 1 "My Core", by artist Sofie Layton, 2018, six images realised by photographer Stephen King. Copyright for all images belongs to the authors (Layton S, Biglino G) (2). The images are published with the consent of the person in them.

patient and his heart displayed as part of a larger exhibition (www.insidetheheart.org). The series, emblematic of this journey, powerfully resonated with other patients with CHD. When viewing the photographs in the exhibition during a guided visit with a health psychologist, a group of CHD patients responded immediately to the imagery they discussed, animatedly, how it captured the burden, the continual presence of their heart condition. They saw the size representing their investment in their heart and their health, the impact it had-everything about it was big. The isolation clearly resonated-just them and their heartas did the preciousness of their heart conveyed through the richness of the velvet, their own strength through its boldness and size. They wanted to throw it away, to disengage from it for just a moment but then they needed to catch it once more, to keep it safe, always there. Patients valued how the photographs externalised something that was inside them, how it made visible to everybody else something that had up until then been invisible to the outside world and something only they could feel and experience. The artwork thus becomes a catalyst, it provides language and visual references where words fail (or are too difficult to utter) and presents the opportunity for other patients to share their experiences.

The artistic translation process allows a complex feeling or set of emotions to be conveyed and shared. Cocreated photographic images have, for instance, been used to describe intensity of pain and subjective perceptions where more objective scales fail to capture the uniqueness of an individual's experience (5). The artistic approach is increasingly recognised as an effective way to complement the purely medical view of an individual where the focus shifts from the sickness to the person (6). A recent report from the WHO about the role of the arts in improving health and wellbeing (7) highlighted how key components of the engagement with the arts (including evocation of emotion, involvement of the imagination and connecting with themes of health) can lead to psychological, physiological, social and behavioural responses, including reduced loneliness, better coping mechanisms and increased engagement with health services.

In the specific context of teenagers and young adults living with CHD and navigating complex phases in their lives, such as transitioning into adulthood and gaining ownership of their condition, engaging with imagery that is both accessible and stimulating, and importantly rooted in a process of sharing and translating lived experiences, can offer reassurance and opportunities to articulate and share. That resonance, that prompt provided by the artwork, enables both crystallisation of an experience and for it to be woven into a narrative, although such engagement should, at least initially, be carried out with appropriately trained psychologists or other professionals who can provide any necessary support. When the narrative is authentic it is 
recognised, both by those who share it (other patients) and those who witness it (families and clinicians), offering a new medium through which to explore it.

\section{Acknowledgments}

The Heart of the Matter (www.insidetheheart.org) was conceived by artist Sofie Layton and bioengineer Giovanni Biglino and developed with health psychologist Jo Wray. The work was produced by Susie Hall (GOSH Arts), Nicky Petto and Anna Ledgard in association with Artsadmin. The exhibition was presented in venues across different cities in the UK between March and November 2018.

Funding: The work was supported by the Wellcome Trust, the Blavatnik Family Foundation, Above\&Beyond, Great Ormond Street Hospital Children's Charity and using public funding by the National Lottery through Arts Council England. With thanks to RapidformRCA and 3D Life Print.

\section{Footnote}

Peer Review File: Available at https://dx.doi.org/10.21037/ cdt-21-387

Conflicts of Interest: All authors have completed the ICMJE uniform disclosure form (available at https://dx.doi. org/10.21037/cdt-21-387). Jo Wray is supported by the Great Ormond Street Hospital NIHR Biomedical Research Centre. All authors report that the work was supported by the Wellcome Trust, the Blavatnik Family Foundation, Above\&Beyond, Great Ormond Street Hospital Children's Charity and using public funding by the National Lottery through Arts Council England. With thanks to RapidformRCA and 3D Life Print. The authors have no other conflicts of interest to declare.

Ethical Statement: The authors are accountable for all aspects of the work in ensuring that questions related to the accuracy or integrity of any part of the work are appropriately investigated and resolved. All workshop participants provided written consent for their participation and the use of their artwork. The images are published with the consent of the person in them.

Open Access Statement: This is an Open Access article distributed in accordance with the Creative Commons Attribution-NonCommercial-NoDerivs 4.0 International License (CC BY-NC-ND 4.0), which permits the noncommercial replication and distribution of the article with the strict proviso that no changes or edits are made and the original work is properly cited (including links to both the formal publication through the relevant DOI and the license). See: https://creativecommons.org/licenses/by-nc-nd/4.0/.

\section{References}

1. Cornett L, Simms J. At the 'heart' of the matter: an exploration of the psychological impact of living with congenital heart disease in adulthood. J Health Psychol 2014;19:393-406.

2. Layton S, Biglino G. The Heart of the Matter Exhibition Catalogue GOSH Arts. 2018.

3. Layton S, Wray J, Leaver LK, et al. Exploring the uniqueness of congenital heart disease: an interdisciplinary conversation. J Appl Arts Health 2016;7:77-91.

4. Biglino G, Layton S, Wray J. Beyond Heart Symbolism: Artistic Representation of Narratives of Congenital Heart Disease. JAMA 2017;318:1740-2.

5. Padfield D, Omand H, Semino E, et al. Images as catalysts for meaning-making in medical pain encounters: a multidisciplinary analysis. Med Humanit 2018;44:74-81.

6. Stuckey HL, Nobel J. The connection between art, healing, and public health: a review of current literature. Am J Public Health 2010;100:254-63.

7. Fancourt D, Finn S. What is the evidence on the role of the arts in improving health and well-being? A scoping review. WHO Health Evidence Network Synthesis Reports. 2019.
Cite this article as: Wray J, Layton S, Biglino G. My Core: conveying the everyday normality of living with congenital heart disease. Cardiovasc Diagn Ther 2021;11(6):1436-1438. doi: $10.21037 /$ cdt-21-387 